\title{
A Comprehensive Meta-analysis of the Prevalence of Autism Spectrum Disorders
}

\author{
Guo Huifen ${ }^{1,2, ~ *, ~ M a ~ Y a n ~}{ }^{1,2}$, Wang Aizhu ${ }^{1,2}$, Xiang Zhu ${ }^{1,2}$ \\ ${ }^{1}$ School of Computer and Information Science, Chongqing Normal University, Chongqing, China \\ ${ }^{2}$ Wisdom Education Research Institute, Chongqing Normal University, Chongqing, China \\ Email address: \\ 2508419105@qq.com (Guo Huifen),153836619@qq.com (Ma Yan),2385865470@qq.com (Wang Aizhu), \\ 1093898765@qq.com (Xiang Zhu) \\ ${ }^{*}$ Corresponding author
}

\section{To cite this article:}

Guo Huifen, Ma Yan, Wang Aizhu, Xiang Zhu. A Comprehensive Meta-analysis of the Prevalence of Autism Spectrum Disorders. Psychology and Behavioral Sciences. Vol. 10, No. 3, 2021, pp. 104-111. doi: 10.11648/j.pbs.20211003.11

Received: March 23, 2021; Accepted: May 10, 2021; Published: May 24, 2021

\begin{abstract}
Background: There are conflicting reports on the prevalence of ASDs in mainland China (China thereafter) and abroad, and no scholars have compared the prevalence in China and abroad. Further studies are needed to clarify the changes in the prevalence rate and compare the prevalence rates at home and abroad. Objective: In order to compare the prevalence of autism at home and abroad, and compare diagnostic tools, diagnostic criteria and other aspects. So far, no scholar has compared the prevalence of autism in China and abroad. Chinese scholars have hardly studied the comprehensive prevalence in China, and the prevalence of autism is conflicting. Methods: I used the Meta-analysis to carry out the research. Firstly, literature was retrieved according to key words and extracted according to screening criteria. Secondly, forest plots and funnel plots were drawn to analyze their significance and heterogeneity. Results: Based on diagnostic criteria the pooled prevalence of ASDs, 73.6 per 10,000 in China (95\% CI: $14.22-77.96$ per $10,000 \mathrm{I}^{2}=80.95 \%$ ), and 98.8 per 10,000 abroad (95\% CI: $22.35-127.04$ per 10000 per $98.14 \%, \mathrm{I}^{2}=98.14 \%$ ). Subgroup analyses revealed significant difference in the prevalence of ASDs between genders. Moreover, the prevalence of males far exceeds that of females both in China and abroad. Conclusion: There are significant differences in the prevalence of autism at home and abroad, and there are also large differences in diagnostic criteria and diagnostic tools. There are significant differences between developing regions and underdeveloped regions, and there are also differences in the prevalence of autism between different genders, but the differences are not significant. In addition, the number of people suffering from autism may gradually increase in the future, and the number of people who understand autism will become wider and wider, the aging phenomenon of autism will gradually increase, and the causes of autism will become more and more complicated.
\end{abstract}

Keywords: Autism Spectrum Disorders, Prevalence, Meta-analysis, Subgroup Analysis, Comparative Study

\section{Introduction}

Autism spectrum disorders (ASDs) refer to a group of pervasive developmental disorders caused by a combination of genetic and environmental factors. They are often associated with pronounced personal suffering and heavy burden of care to families and society. [1] ASDs consist of several subtypes, with autism being the core and the most common one. ASDs usually occur in infancy [2] and present with complex symptoms. Children with ASDs usually have difficulties in understanding language and social behaviors; parental concern is often centered around their children presenting abnormal behaviors, such as mutism, echolalia and lack of expressive emotion.

Accurate estimation of the prevalence of ASDs is not only very important for the health sectors to understand its impact on the general population and provide appropriate resource allocations., but also provide references and suggestions for future research and practice. The sample sizes of studies estimating ASD were fairly large ranging from 8896 to 4950 333 individuals in USA. Estimates of AD varied from 0.740.5 per 10000 , with a median of 11 per 10000 . [3]. The apparent growing trend could be partly explained by the 
discrepancy in age of subjects, diagnostic criteria and sampling methods. In addition, there is wide variation in the prevalence of ASDs between countries. For instance, the prevalence of autism was 34 per 10,000 in USA [4]versus 99 per 10,000 in the UK [5]. Prevalence studies of ASDs have shown conflicting findings in China and abroad. Moreover, most studies were published in Chinese-language journals that are not accessible to international readership. More than 20 ASDs prevalence studies have been recently published in Chinese, which have enhanced the epidemiological dataset, but are generally not accessible to the international readership. In China, there are only a few areas for epidemiological surveys, and there is no national epidemiological report. [6] In China, there are few areas of epidemiological investigation, and the research on autism is relatively simple. There is not only no national epidemiological report, but also no comparative study on the prevalence of autism at home and abroad. Therefore, we set out to conduct this comprehensive meta-analysis of the pooled prevalence of ASDs in China and also to examine its mediating factors (e.g., gender, region, study period, and diagnostic tools used).

\section{Methods}

\subsection{Search Strategy}

The literature search process is shown in Figure 1.
Investigator searched the literature using PubMed, EMBASE, PsycINFO, China National Knowledge Infrastructure, Chinese biomedical literature service system (SinoMed). Search terms included ('autism' or 'autistic disorder' or 'autism spectrum conditions' or 'pervasive developmental disorders' or 'Asperger') and ('epidemiology' or 'cross-sectional study' or 'prevalence' or 'rate'). In order to avoid missing any studies, the reference lists of relevant review or meta-analyses were searched manually. If more than one publication was reported based on the same dataset, only the paper with complete data was included.

\subsection{Selection Criteria}

Inclusion criteria were as follows: 1) cross-sectional or cohort studies conducted in mainland China (China thereafter) and abroad (only baseline data were extracted in the latter);2) participants aged $\leq 18$ years; 3 ) the diagnosis of ASD was established by either clinical diagnostic criteria (such as the Diagnostic and Statistical Manual of Mental Disorder (DSM), Chinese Classification of Mental Disorder (CCMD) or International Classification of Disease (ICD) systems), or screening tools (such as the Clancy Autism Behavior Scale (CABS), Children Autism Spectrum Test (CAST) and Checklist for Autism in Toddlers (CHAT)). Both clinical diagnostic criteria and screening tools on ASDs and autism were involved because they have been widely used in epidemiology and clinical practice in China and abroad.

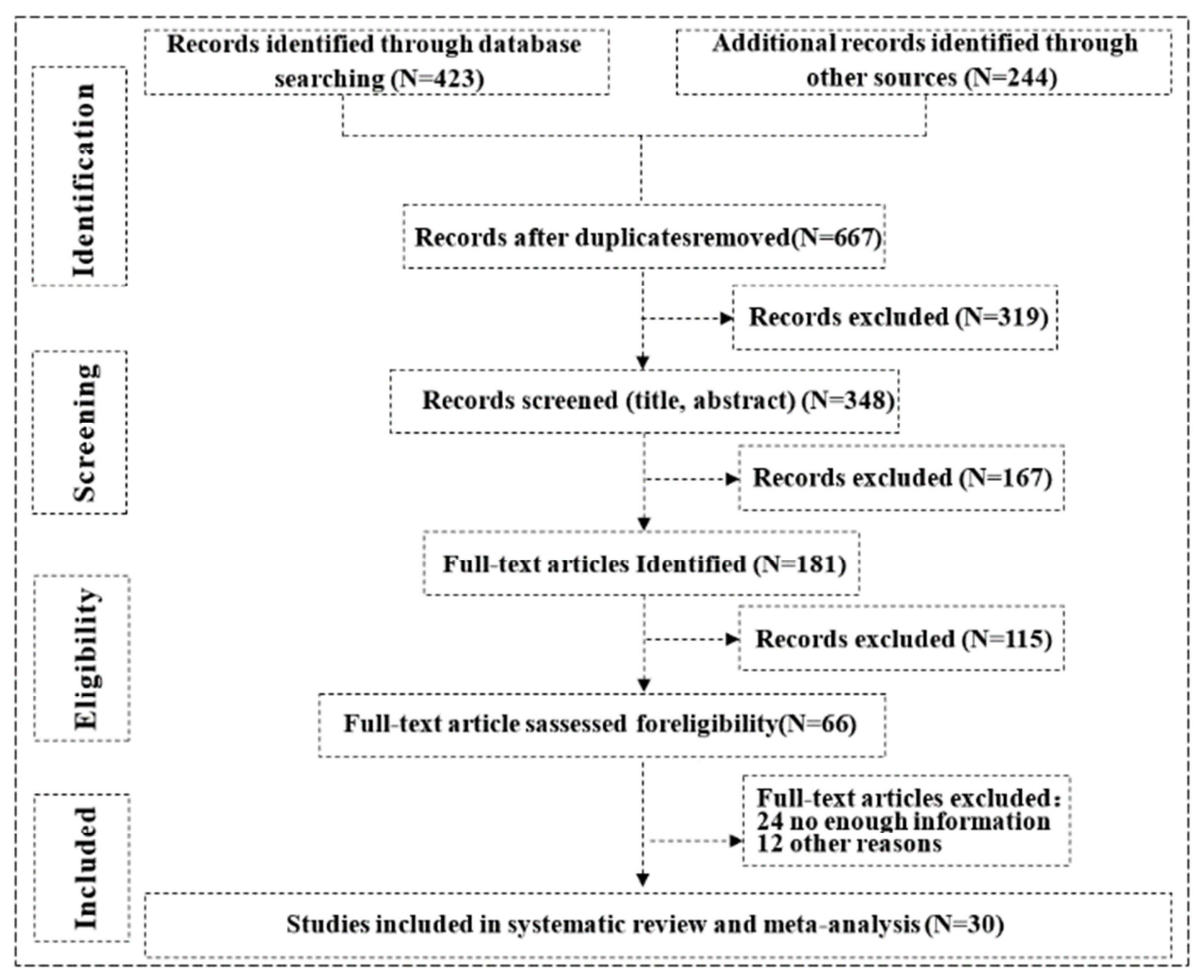

Figure 1. Flow chart of the study.

Of 667 eligible papers identified in literature search, 30 fulfilled the inclusion criteria after screening the titles, abstracts and full texts, and removing the duplicates (Figure 1). Five of these studies were published in English and thirty-nine in Chinese. Their sample size ranged from 737 to $3,536,276$ subjects and 30 studies had a sample size greater than 5,000 . The 44 included studies had a total of 3,926,642 subjects of which $30.12 \%$ were females. Fifteen studies 
reported the prevalence of autism in China, and 15 studies mainly reported the prevalence of autism abroad.

\section{Results}

\subsection{Characteristics of Studies}

The characteristics of the included studies are shown in Table 1. These studies were conducted between 2001 and 2015. Mean age of the subjects ranged from 3 to 8 years, with the median age of 6 years. Sixteen studies were conducted in urban areas $(53.3 \%)$ and the others were in both urban and rural areas (urban/rural were defined by the studies included in the meta-analysis). Nine studies were conducted in south China, Six in north China, eight studies in developed areas abroad, and seven study in underdeveloped areas abroad. The CABS and CHAT (6/15) was the most commonly used screening tool in China and abroad is ASCQ.

Table 1. Characteristic of the Included Studies.

\begin{tabular}{|c|c|c|c|c|c|c|c|}
\hline Study name (Year) & Region & $\begin{array}{l}\text { Sample } \\
\text { Size }\end{array}$ & $\begin{array}{l}\text { Area } \\
\text { (Urban/ } \\
\text { Rural) }\end{array}$ & Age (Years) & Sample & $\begin{array}{l}\text { Screening } \\
\text { diagnostic } \\
\text { tools }\end{array}$ & $\begin{array}{l}\text { Diagnostic } \\
\text { criteria }\end{array}$ \\
\hline Zhang et al. 2007 & Wuxi, China & 25521 & Urban & 1 to 6 & $\mathrm{C}$ & CHAT & DSM-IV \\
\hline Pu et al. 2009 & Guiyang, China & 3211 & Urban & 2 to 6 & $\mathrm{~K}$ & CABS & DSM-IV \\
\hline Huang et al. 2009 & Tianjin, China & 8000 & Urban & 1.5 to 3 & G & CHAT & DSM-IV \\
\hline Liang et al. 2009 & Maoming, China & 2485 & Urban & 3 to 6 & $\mathrm{~K}$ & CABS & ICD-10 \\
\hline Yu et al. 2009 & Ha'erbin, China & 7059 & Mixed & 2 to 6 & $\mathrm{~K}$ & CABS & DSM-IV \\
\hline Li et al. 2012 & Changchun, China & 9714 & Urban & 0 to 6 & $\mathrm{G}$ & $\mathrm{ABC}$ & CCMD-3 \\
\hline Chen et al. 2012 & Zhuhai, China & 4754 & Both & 1.5 to 3 & REG & CHAT & DSM-IV \\
\hline Duan et al. 2012 & Zhengzhou, China & 1000 & NA & 1.5 to 3 & $\mathrm{C}$ & CHAT & DSM-IV \\
\hline Gao et al. 2013 & Zhongshan, China & 12804 & Both & 3 to 6 & $\mathrm{~K}$ & CABS & NA \\
\hline Den get al. 2013 & Hengyang, China & 7041 & Both & 2 to 6 & $\mathrm{~K}$ & CABS & DSM-IV \\
\hline Wang et al. 2014 & Zaozhuang, China & 6634 & NA & 2 to 6 & $\mathrm{~K}$ & CABS & DSM-V \\
\hline Sun et al. 2014 & Beijing, China & 737 & Urban & 6 to 11 & PS & CAST & ADI-R \\
\hline Cheng et al. 2014 & Ningbo, China & 12123 & Both & 1 to 6 & $\mathrm{C}$ & CHAT & DSM-IV \\
\hline Chakrabarti et al. 2001 & Staffordshire, U.K. & 15500 & Urban & 2.5 to 6.5 & PS & NA & ADI-R \\
\hline Bertrand et al. 2001 & New Jersey, U.S.A. & 17792 & Mixed & 3 to 10 & PS & NA & DSM-V \\
\hline Honda et al. 2005 & Yokohama, Japan & 35716 & Mixed & 0 to 5 & REG & SCQ & ICD-10 \\
\hline Chakrabarti et al. 2005 & Stafford, U.K. & 10903 & Urban & 4 to 6 & REG & NA & NA \\
\hline Baird et al. 2006 & Thames, U.K. & 56946 & Urban & 9 to 10 & PS & SCQ & ADI-R \\
\hline Oliveira et al. 2007 & Portugal & 10910 & Mixed & 6 to 9 & PS & CARS & DSM-IV \\
\hline Ellefsen et al. 2007 & The Faroe Islands & 7689 & Mixed & 8 to 17 & REG & ASSQ & ICD-10 \\
\hline Kawamura et al. 2008 & Toyota, Japan & 12589 & Urban & 0 to 3 & PS & NA & ICD-10 \\
\hline Kim et al. 2011 & Goyang, Korea & 55266 & Urban & 7 to 12 & PS & ASSQ & ADI-R \\
\hline Totsika et al. 2011 & U.K. & 18415 & NA & 5 to 16 & PS & NA & ICD-10 \\
\hline Samadi et al. 2012 & Iran & 3536276 & NA & 6 to 13 & PS & SCQ & ADI-R \\
\hline Nygren et al. 2012 & Gothenburg, Sweden & 5007 & Urban & 0 to 2 & REG & M-CHAT & DSM-IV \\
\hline Saemundsen et al. 2013 & Iceland & 22229 & Urban & 0 to 15 & PS & ADOS & ADI-R \\
\hline Nordenbaek et al. 2014 & Danish & 7296 & Mixed & 3 to 14 & REG & NA & DSM-IV \\
\hline Sun et al. 2014 & Cambridgeshire, U.K. & 3283 & Urban & 5 to 11 & REG & NA & ICD-10 \\
\hline
\end{tabular}

* Rural/urban areas were defined by included studies. Sample screen: C, clinical service; G, general population; K, kindergarten; PS, population sample; REG, registration data; Screening diagnostic tools: ABC, Autism Behavior Checklist; CABS, Clancy Autism Behavior Scale; CARS, Childhood Autism Rating Scale; CHAT, Checklist for Autism in Toddlers; M-CHAT, Modified Checklist for Autism in Toddlers; CAST, Children Autism Spectrum Test; ASSQ, high function Autism Spectrum screening questionnaire; Diagnostic criteria: ADI-R, Autism Diagnostic Interview-Revised; CCMD-3, Chinese Classification of Mental Disorders, 3rd edition; DSM-IV, Diagnostic and Statistical Manual of Mental Disorders, 4th edition; DSM-V, Diagnostic and Statistical Manual of Mental Disorders, 5th edition; ICD-10, International Classification of Diseases, 10th revision;

\subsection{Comprehensive Effect Sizes}

As shown in Table 2, the study has heterogeneity $\left(\mathrm{I}^{2}\right.$ : 97.582), so the random effect is selected, the combined effect value is $0.323,95 \% \mathrm{CI}: 21-49.7$ per 10,000 , the absolute value of $\mathrm{Z}(5.127)$ is greater than 1.96 and $\mathrm{P}<0.1$, indicating that there is a significant difference in the study.

\subsection{Analysis of Autism Subgroups in China and Abroad}

As shown in Table 3, the prevalence rate of autism in 15 domestic studies is 73.6 per 10,000 population, 95\% confidence interval is $14.22-77.96$ per 10,000 population, and
$\mathrm{I}^{2}$ is $80.95 \%$. The prevalence rate of autism in males (59 per $10,000)$ was higher than that in females $(130$ per 10,000$)$. The prevalence rate of autism in urban areas $(860$ per 10,000$)$ was about 1.5 times higher than that in rural areas (63 per $10,000)$. The prevalence rate of autism in the north of China (870 per 10,000$)$ was higher than that in the south $(71.6$ per $10,000)$. The prevalence rate of autism in the north of China was higher than that in the south $(716$ per 10,000$)$. The prevalence rate of autism diagnosed with CAST (91.4 per $10,000)$ was higher than that with CABS $(65.8$ per 10,000$)$, $\mathrm{ABC}(48.6$ per 10,000$)$ and CHAT $(41.2$ per 10,000$)$. The prevalence rate of autism with less than 2 months of study 
(85.2 per 10,000) was higher than that with more than 2 months of study $(85.2$ per 10,000). The prevalence rate of autism diagnosed with CAST $(91.4$ per 10,000) was higher than that with CABS (458 per 10,000), $\mathrm{ABC}(48.6$ per 10,000$)$ and CHAT (41.2 per 10,000). The prevalence rate of autism with less than 2 months of study was higher than that with more than 2 months of study. The prevalence rate of patients aged 0-6 years $(70.9$ per 10,000$)$ was lower than that of $7-11$ years old (91.4 per 10,000).

As shown in Table 4, the prevalence rate of autism in 15 foreign studies is 98.8 per 10,000 people, the $95 \% \mathrm{CI}$ : 22.35-127.04 per 10,000 , and $\mathrm{I}^{2}$ is $98.14 \%$. The prevalence rate of autism in men (749 per 10,000) was about three times higher than that in women (239 per 10,000). The prevalence rate of autism in urban areas (113.6 per 10,000) was much higher than that in rural areas (434 per 10,000). Studies conducted before 2010 showed that the prevalence rate of autism was 67.9 per 10,000 people, while studies after 2010 increased to 134.2 per 10,000 . The prevalence rate in developed areas was significantly different from that in less developed areas. The prevalence rate in developed areas was 84 per 10,000 , and that in underdeveloped areas was 1157 per 10,000 . The prevalence rate of ICD-10 (101 per 10,000) was higher than that of DSM-IV (61.6 per 10,000) and ADI-R (834 per 10,000). There were significant differences in the prevalence of autism among different diagnostic tools. The prevalence rate of autism using ASSCQ (160 per 10000$)$ was much higher than that of SCQ (33 per 10,000), M-CHAT (800 per 10,000) and CARS (248 per 10,000). The prevalence rate of autism in patients with less than 2 months of study was higher than that in patients with more than 2 months of study (11.0 per 10,000). The prevalence rate of autism in patients with less than 2 months of study was higher than that in patients with more than 2 months of study. The prevalence rate of autism was different in different age groups, and the prevalence rate of patients aged $0-10$ years old (71 per 10,000) was lower than that of 0-16 years old (139 per 10,000).
Study name

$\begin{array}{lrrrrr} & \begin{array}{r}\text { Odds } \\ \text { ratio }\end{array} & \begin{array}{c}\text { Lower } \\ \text { limit }\end{array} & \begin{array}{c}\text { Upper } \\ \text { limit }\end{array} & \begin{array}{r}\text { Z-Value } \\ \text { Z-Value }\end{array} \\ \text { Zhang et al. } & 0.265 & 0.171 & 0.412 & -5.893 & 0.000 \\ \text { Pu et al. } & 0.591 & 0.274 & 1.275 & -1.341 & 0.180 \\ \text { Huang et al. } & 0.014 & 0.006 & 0.034 & -9.704 & 0.000 \\ \text { Liang et al. } & 0.331 & 0.129 & 0.848 & -2.305 & 0.021 \\ \text { Yu et al. } & 1.067 & 0.527 & 2.159 & 0.180 & 0.857 \\ \text { Wei et al. } & 0.699 & 0.266 & 1.839 & -0.725 & 0.469 \\ \text { Li et al. } & 0.014 & 0.005 & 0.044 & -7.314 & 0.000 \\ \text { Chen et al. } & 0.166 & 0.037 & 0.744 & -2.348 & 0.019 \\ \text { Duan et al. } & 0.284 & 0.059 & 1.372 & -1.566 & 0.117 \\ \text { Gao et al. } & 0.666 & 0.272 & 1.631 & -0.889 & 0.374 \\ \text { Deng rt al. } & 0.380 & 0.213 & 0.676 & -3.292 & 0.001 \\ \text { Wang et al. } & 0.221 & 0.103 & 0.476 & -3.855 & 0.000 \\ \text { Sun et al. } & 1.358 & 0.869 & 2.121 & 1.345 & 0.179 \\ \text { Sun et al. } & 0.051 & 0.022 & 0.116 & -7.050 & 0.000 \\ \text { Cheng et al. } & 0.349 & 0.190 & 0.642 & -3.385 & 0.001 \\ \text { Tian et al. } & 0.181 & 0.076 & 0.432 & -3.848 & 0.000 \\ \text { Chakrabarti et al.1 } & 0.151 & 0.121 & 0.189 & -16.575 & 0.000 \\ \text { Bertrand et al. } & 0.599 & 0.396 & 0.906 & -2.426 & 0.015 \\ \text { Honda et al. } & 0.532 & 0.415 & 0.681 & -5.016 & 0.000 \\ \text { Chakrabarti et al.5 } & 0.435 & 0.269 & 0.703 & -3.396 & 0.001 \\ \text { Baird et al. } & 0.701 & 0.597 & 0.823 & -4.334 & 0.000 \\ \text { Oliveira et al. } & 0.049 & 0.022 & 0.112 & -7.183 & 0.000 \\ \text { Ellefsen et al. } & 0.787 & 0.522 & 1.187 & -1.141 & 0.254 \\ \text { Kawamura et al. } & 0.951 & 0.788 & 1.147 & -0.526 & 0.599 \\ \text { Kim et al. } & 0.092 & 0.062 & 0.135 & -12.095 & 0.000 \\ \text { Totsika et al. } & 0.077 & 0.058 & 0.102 & -17.576 & 0.000 \\ \text { Samadi et al. } & 2.598 & 2.283 & 2.957 & 14.465 & 0.000 \\ \text { Nygren et al. } & 1.126 & 0.734 & 1.727 & 0.544 & 0.586 \\ \text { Saemundsen et al. } & 0.570 & 0.456 & 0.713 & -4.927 & 0.000 \\ \text { Nordenbaek et al. } & 1.000 & 0.433 & 2.308 & 0.000 & 1.000 \\ & 0.652 & 0.612 & 0.694 & -13.465 & 0.000 \\ & & & & & \\ & & & \end{array}$

Statistics for each study

000

021

857

469

0.019

0.117

0.374

0.179

0.000

0.001

0.015

0.000

0.001

0.000

0.254

0.599

0.000

0.000

0.000

0.000

1.000

0.000

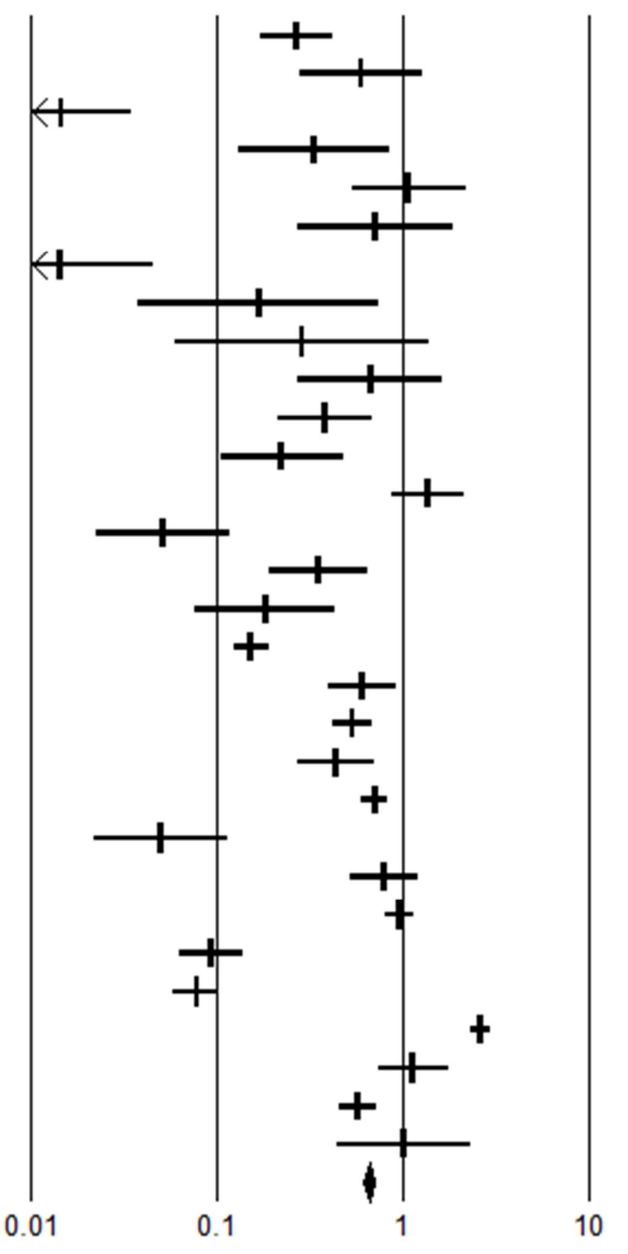

Favours A

Figure 2. Forest Plot. 
Table 2. Comparative Effect Sizes.

\begin{tabular}{|c|c|c|c|c|c|c|c|}
\hline \multirow{2}{*}{ Model } & \multirow{2}{*}{$\begin{array}{l}\text { Effect } \\
\text { size }\end{array}$} & \multicolumn{2}{|l|}{$95 \%$ CI } & \multicolumn{2}{|c|}{ Heterogeneity } & \multirow{2}{*}{$I^{2}$} & \multirow{2}{*}{ Number Studies } \\
\hline & & Lower limit (per 10000) & Upper limit (per 10000) & Z-value & P-value & & \\
\hline Fixed & 0.652 & 61.2 & 69.4 & -13.465 & $<0.1$ & \multirow{2}{*}{97.582} & \multirow{2}{*}{30} \\
\hline Random & 0.323 & 21 & 49.7 & -5.127 & $<0.1$ & & \\
\hline
\end{tabular}

Table 3. Subgroup Analysis Based on Chinese Diagnostic Criteria for ASDs.

\begin{tabular}{|c|c|c|c|c|c|c|c|c|c|c|}
\hline & $\begin{array}{l}\text { Variable } \\
\text { name }\end{array}$ & Event & $\begin{array}{l}\text { Event } \\
\text { sample size }\end{array}$ & P-value & $I^{2}(\%)$ & $\begin{array}{l}\text { Prevalence } \\
(\text { per 10000) }\end{array}$ & $\begin{array}{l}\text { Lower limit } \\
\text { (per 10000) }\end{array}$ & $\begin{array}{l}\text { Upper limit } \\
\text { (per 10000) }\end{array}$ & Z-value & P-value \\
\hline \multirow{2}{*}{ Gender } & Male & 280 & 3545 & $<0.1$ & 87.911 & 59 & 11.9 & 38.9 & -5.083 & \multirow{2}{*}{$<0.1$} \\
\hline & Female & 54 & 808 & $<0.1$ & 88.658 & 13 & 9.4 & 34.8 & -5.14 & \\
\hline \multirow{2}{*}{ Area } & Urban & 114 & 1194 & $<0.1$ & 89.626 & 86 & 10.8 & 41 & -4.591 & \multirow{2}{*}{$<0.1$} \\
\hline & Rural & 220 & 269 & $<0.1$ & 55.815 & 63 & 28.5 & 80.8 & -2.765 & \\
\hline \multirow{2}{*}{ Study time } & $\leq 2010$ & 105 & 885 & $<0.1$ & 95.018 & 44 & 27 & 172 & -1.886 & \multirow{2}{*}{$<0.1$} \\
\hline & $>2010$ & 229 & 578 & $<0.1$ & 85.346 & 88 & 11.9 & 429 & -4.541 & \\
\hline \multirow{2}{*}{$\begin{array}{l}\text { Study } \\
\text { site }\end{array}$} & North & 136 & 804 & $<0.1$ & 93.857 & 87 & 22 & 35.8 & -3.412 & \multirow[b]{2}{*}{$<0.1$} \\
\hline & South & 198 & 659 & 0.411 & 2.784 & 71.6 & 28.7 & 47.3 & -7.844 & \\
\hline \multirow{3}{*}{$\begin{array}{l}\text { Diagnostic } \\
\text { criteria }\end{array}$} & CCMD & 54 & 323 & $<0.1$ & 91.731 & 67.7 & 4 & 63.1 & -2.322 & \multirow{3}{*}{$<0.1$} \\
\hline & DSM-IV & 235 & 1041 & $<0.1$ & 86.969 & 110 & 14.4 & 54.3 & -3.767 & \\
\hline & ICD-10 & 54 & 149 & $<0.1$ & 83.597 & 129.5 & 12.9 & 84.8 & -2.305 & \\
\hline \multirow{4}{*}{$\begin{array}{l}\text { Diagnostic } \\
\text { tools }\end{array}$} & $\mathrm{ABC}$ & 71 & 94 & $<0.1$ & 98.115 & 48.6 & 0.5 & 4.4 & -7.314 & \multirow{4}{*}{$<0.1$} \\
\hline & CABS & 169 & 620 & $<0.1$ & 54.029 & 65.8 & 30.3 & 75.6 & -3.156 & \\
\hline & CHAT & 126 & 580 & $<0.1$ & 89.489 & 41.2 & 6.6 & 52.9 & -3.156 & \\
\hline & CAST & 39 & 148 & $<0.1$ & 76.874 & 91.4 & 2.7 & 33.2 & -3.69 & \\
\hline \multirow{2}{*}{ Test time } & $\leq 2$ months & 44 & 364 & $<0.1$ & 95.018 & 85.2 & 2.7 & 107.2 & -1.886 & \multirow{2}{*}{$<0.1$} \\
\hline & $>2$ months & 163 & 520 & $<0.1$ & 85.346 & 61.7 & 11.9 & 42.9 & -4.541 & \\
\hline Age & $0-6$ & 295 & 1315 & $<0.1$ & 87.936 & 70.9 & 13 & 46.1 & -4.359 & \multirow{2}{*}{$<0.1$} \\
\hline (years) & $7-11$ & 39 & 148 & $<0.1$ & 89.879 & 91.4 & 21 & 37.1 & -3.785 & \\
\hline
\end{tabular}

Table 4. Subgroup Analysis Based on Foreign Diagnostic Criteria for ASDs.

\begin{tabular}{|c|c|c|c|c|c|c|c|c|c|c|}
\hline & Variable name & Event & $\begin{array}{l}\text { Event } \\
\text { sample size }\end{array}$ & P-value & $I^{2}(\%)$ & $\begin{array}{l}\text { Prevalence } \\
\text { (per 10000) }\end{array}$ & $\begin{array}{l}\text { Lower limit } \\
\text { (per 10000) }\end{array}$ & $\begin{array}{l}\text { Upper limit } \\
\text { (per 10000) }\end{array}$ & Z-value & P-value \\
\hline \multirow{2}{*}{ Gender } & Male & 892 & 3902 & $<0.1$ & 98.581 & 74.9 & 26 & 82.9 & -2.595 & \multirow{2}{*}{$<0.1$} \\
\hline & Female & 295 & 1190 & $<0.1$ & 98.231 & 23.9 & 15 & 49.6 & -2.164 & \\
\hline \multirow{2}{*}{ Area } & Urban & 703 & 2640 & $<0.1$ & 97.491 & 113.6 & 27.4 & 88.3 & -2.375 & \multirow{2}{*}{$<0.1$} \\
\hline & Rural & 448 & 2452 & $<0.1$ & 99.001 & 43.4 & 13.3 & 138.5 & -1.415 & \\
\hline \multirow{2}{*}{ Study time } & $\leq 2010$ & 589 & 2402 & $<0.1$ & 98.710 & 67.9 & 24.6 & 120.7 & -1.496 & \multirow{2}{*}{$<0.1$} \\
\hline & $>2010$ & 562 & 2690 & $<0.1$ & 97.779 & 134.2 & 16.8 & 79.8 & -2.529 & \\
\hline $\begin{array}{l}\text { Study } \\
\text { site }\end{array}$ & undeveloped areas & 689 & 2323 & $<0.1$ & 97.768 & 115.7 & 20.3 & 82.9 & -2.482 & $<0.1$ \\
\hline \multirow{3}{*}{$\begin{array}{l}\text { Diagnostic } \\
\text { criteria }\end{array}$} & ADI-R & 571 & 3317 & $<0.1$ & 99.247 & 83.4 & 16.8 & 123.5 & -1.546 & \multirow{3}{*}{$<0.1$} \\
\hline & DSM- IV & 684 & 1702 & $<0.1$ & 95.576 & 61.6 & 60 & 252.9 & -0.99 & \\
\hline & ICD-10 & 602 & 2303 & $<0.1$ & 98.282 & 101 & 19.8 & 139.9 & -1.286 & \\
\hline \multirow{3}{*}{$\begin{array}{l}\text { Diagnostic } \\
\text { tools }\end{array}$} & CARS & 80 & 126 & $<0.1$ & 97.741 & 24.8 & 18 & 74.6 & -2.77 & \multirow{3}{*}{$<0.1$} \\
\hline & M-CHAT & 40 & 85 & $<0.1$ & 97.710 & 80 & 25.6 & 100.4 & -1.948 & \\
\hline & ASSCQ & 143 & 425 & $<0.1$ & 98.207 & 160 & 3.3 & 220.8 & -1.223 & \\
\hline \multirow{2}{*}{ Test time } & $\leq 2$ months & 53 & 1144 & $<0.1$ & 98.710 & 112.7 & 24.6 & 120.7 & -1.496 & \multirow{2}{*}{$<0.1$} \\
\hline & $>2$ months & 542 & 1894 & $<0.1$ & 97.779 & 110 & 16.8 & 79.8 & -2.529 & \\
\hline \multirow{2}{*}{ Age (years) } & $\leq 10$ & 588 & 2394 & $<0.1$ & 96.741 & 71 & 25 & 73.9 & -3.055 & \multirow{2}{*}{$<0.1$} \\
\hline & $\leq 16$ & 592 & 2698 & $<0.1$ & 99.133 & 139 & 16.3 & 168.8 & -1.083 & \\
\hline
\end{tabular}

\subsection{Heterogeneity}

Heterogeneity refers to the difference between the real effect quantity, the long vertical bar with 1 in the middle represents the effect quantity is 0 , and the left and right interval containing 0 means that it is not significant [7]. As shown in figure 2, Lower limit and Upper limit correspond to the values at both ends of the black horizontal line in the diagram. As long as the right end of the horizontal line exceeds 1 means that the confidence interval contains 0 is not significant, on the contrary, it is significant if it does not contain 0 . The black vertical bar is the point estimate of the amount of effect, that is, the value of Odds ratio (OR), OR > 1 , there are more events affected by certain conditions, while $\mathrm{OR}<1$, fewer events are affected by certain conditions.

\subsection{Publication Bias}

The publication error can be identified by the funnel chart, which takes one percent of the standard error as the vertical axis, the larger the number of samples, the smaller the standard error, the more symmetrical the funnel shape; the effect size as the horizontal axis, the shape is similar to the 
inverted funnel [8]. If there is no balance or symmetry between the left and the right, it means that the included article is missing. The study with large sample number is distributed at the top and close to the average effect, while the study with small sample number is distributed at the bottom and dispersed with the average effect. As shown in figure 3, each circle represents a document, the hollow circle represents the literature that has been included in the meta-analysis, and the solid circle represents the literature that needs to be filled. In the funnel chart, the larger the number of solid circles, the greater the publication error of the study, indicating that some related literatures are not included in the meta-analysis.

\section{Funnel Plot of Standard Error by Log odds ratio}

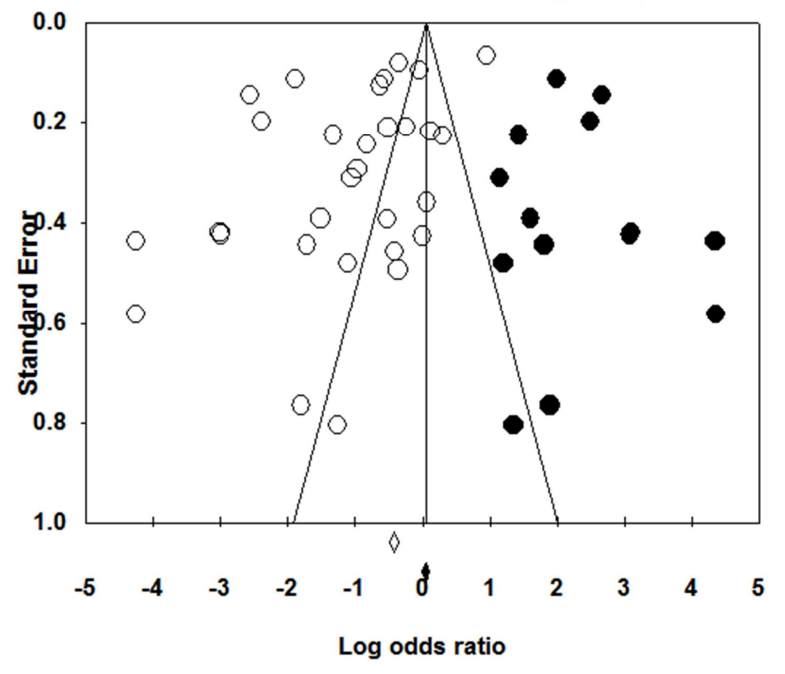

Figure 3. Funnel Plot.

\section{Conclusion}

\subsection{There are Significant Differences in Autism and Prevalence of Autism Between Men and Women}

The meta-analysis of autism at home and abroad included 30 studies and 3,926,642 subjects, covering 15 provinces/cities in China and 15 foreign countries/states/regions. Due to the differences in sampling methods, diagnostic tools and diagnostic criteria, there are also great differences in prevalence among different studies. The study found that the prevalence rate of autism based on clinical diagnostic criteria in China is 59.8 per 10,000 , which is lower than that of 820 per 10,000 abroad and also lower than that of other countries in the world. This finding is similar to that of Chiarotti [9], the median prevalence rate of autism in Europe is 61.9 per 10,000 [10], the prevalence rate of autism in the USA is 110 per 10,000 [11], 264 per 10,000 people in South Korea have autism [12], and 181 autism per 10,000 people in Japan [13].

In foreign countries, the prevalence rate of males is 3 times higher than that of females, while the prevalence rate of domestic males is 4.5 times higher than that of females. In addition, the study found that there were significant differences in the prevalence of autism between regions. There was no significant difference in the prevalence rate between urban areas $(860 / 10,000)$ and rural areas $(636 / 10,000)$. However, the prevalence rate in foreign urban areas $(113.6 / 10,000)$ was much higher than that in rural areas $(43.4 / 10,000)$. There was a significant difference in the prevalence rate between the south (71.6 / 10000$)$ and the north (87 / 10 000) of China, but there was no significant difference between the developed areas $(840 / 10$ 000) and the less developed areas (1157/ 10 000). Regional differences will lead to differences in environmental stress, parents' education and so on. Families in foreign developed areas pay more attention to autism and will take timely intervention measures. this is one of the reasons for the great difference in prevalence between developed and less developed areas.

\subsection{There Are Differences in Diagnostic Criteria, Tools and the Prevalence of Autism in Different Age Groups}

There are significant differences in diagnostic criteria-based autism between China and foreign countries. ICD-10, DSM-IV and CCMD are the most commonly used diagnostic criteria in China, while ADI-R, DSM-IV and ICD-10 are the main diagnostic criteria in foreign countries. CAST and CABS are the most commonly used diagnostic tools for autism in China, but they are rarely used in foreign studies, while ASSQ and M-CHAT are widely used abroad, so the differences in diagnostic tools for autism will lead to differences found at home and abroad.

The prevalence rate of autism in children aged 0-6 years old in China is 70.9 / 10000 , while that of children aged 7-11 years old is as high as 91.4/ 10000 , which is inconsistent with the results of the national survey (children aged 4-6 years old have the highest risk) [14]. However, the situation in foreign countries is similar to that in China, the prevalence rate of autism in people less than 10 years old $(71 / 10,000)$ is lower than that in those under 16 years old $(1.39 / 10,000)$. In China, children with autism are usually sent to special schools, which may cause epidemiological investigations to underestimate the prevalence of autism in school-age children. In addition, screening tools such as CABS, which are widely used in China, were originally designed by parents. Parents may want their children to avoid being diagnosed with autism or to reverse their symptoms, leading to an underestimation of the prevalence of autism in self-reported surveys. All of these factors may lead to a relatively low prevalence of autism in the younger age group.

\section{Prospection}

The study uses meta-analysis method to make an in-depth study of autism on the basis of review, and finds that the research on autism has the following trends: the scope and field of research on autism are constantly expanding, resulting in an increase in the number of autistic patients; the problem of the gradual popularization of autism but the underrepresentation of female samples still exists; the increasing age of autistic patients highlights the importance 
of carrying out research on the aging of autism. The causes of autism are from single to multiple, and the symbiotic conditions considered are gradually increasing. Follow-up studies should pay attention to the classification of autism.

\subsection{From Rare to Common}

The prevalence of autism from rare to common is a major trend of its development. [15] the number of people diagnosed with autism due to environmental factors is gradually increasing, and the actual incidence rate may be higher than the prevalence rate. Diagnostic criteria, tools and other diagnostic methods have been continuously optimized, and the number of autistic patients has been increasing with different investigation methods. in the corresponding field of autism research, the number of researchers on autism has also increased, and the attention of autism in society has also been greatly increased. Some influential parents have set up charities for autism, bringing experts interested in autism into the field, and funding for autism has been improved.

The generalization of autism has gradually expanded the sample size in academic research, and the results obtained are more and more accurate, thus attracting more and more funding support, but at present, many measurement methods of autism psychology research lack of high-quality psychological measurement data. Therefore, it is necessary for relevant institutions to integrate medical data, routine data and large-scale collection of detailed personal data into a data link under the protection of personal privacy and ethics. In addition, women are underrepresented in the research sample, so both men and women should be included in the empirical study in the follow-up study, and special topics related to women should be considered, such as puberty, pregnancy, lactation, menopause and so on.

\subsection{From Childhood to Life Span}

Most of the subjects were autistic children, ignoring adult autistic patients. Most adults do not get timely diagnosis and treatment when they suffer from autism and are diagnosed in middle and old age, [16] which leads to less understanding of autism in most medical and health institutions and the lack of health protection for the mental and physical condition of the elderly. The problem of autistic aging is becoming more and more prominent, so the research of autistic elderly patients should follow the research track of autistic children and infants, and need to further study the influence of the age of autism on the incidence of mental and physical diseases. and investigate the causes such as heredity, external pressure, autism and so on; the aging of autism needs to be longitudinally studied from middle age to old age according to the constantly adjusted diagnostic criteria.

\subsection{From Pure to Complex}

Different autism may have different symptoms or causes, even in the same person [17], different origins may cause different core symptoms. Autism can also cause physical and mental harm to patients along with other diseases. Studies have found that autism is often accompanied by mental health problems, autism and hyperactivity disorder in children may also occur, and there may also be phenotypic causality between autism and symbiotic diseases, such as social exclusion or bullying may lead to anxiety and depression and even post-traumatic stress disorder (PTSD), autistic children eating irregularities, sensory sensitivity may have adverse effects on the intestines and stomach. The causes of autism are complex, so it is unreasonable to set up the control group and the experimental group to screen the mental health status of children in special children. Researchers should pay more attention to the symbiotic conditions and the confounding effects that will occur.

There are few studies on mental retardation, educational methods and technical assistance of autism. Most people with autism live in low-and middle-income countries. Culture, race and socioeconomic status not only affect the diagnosis of autism, but also affect their performance. There are also many problems in the diagnosis of autism. For example, the follow-up research on autism may be more and more dominated by big data. Although the sample size is gradually increasing and the statistical methods are becoming more and more complex, there is no unified result as to whether autism is accompanied by dysfunction and language disorder. Follow-up studies can try cross-diagnostic studies; compare different neurodevelopmental groups; distinguish the core cognitive characteristics of autism; and explore the related aspects of mental retardation and poor executive function.

\section{References}

[1] Lemoine, L., \& Schneider, B. (2021). Autism spectrum disorder in French children's literature: An analysis of portrayals of children with autism in the light of the DSM-5. Research in Autism Spectrum Disorders, 80, 101675.

[2] Tan, C., Frewer, V., Cox, G., Williams, K., \& Ure, A. (2021). Prevalence and Age of Onset of Regression in Children with Autism Spectrum Disorder: A Systematic Review and Meta-analytical Update. Autism Research, 14 (3), 582-598.

[3] Elsabbagh, M., Divan, G., Koh, Y. J., Kim, Y. S., Kauchali, S., Marcín, C.,... \& Fombonne, E. (2012). Global prevalence of autism and other pervasive developmental disorders. Autism research, 5 (3), 160-179.

[4] Shaw, K. A., Maenner, M. J., \& Baio, J. (2020). Early identification of autism spectrum disorder among children aged 4 years-Early Autism and Developmental Disabilities Monitoring Network, six sites, United States, 2016. MMWR Surveillance Summaries, 69 (3), 1.

[5] Hosozawa, M., Sacker, A., Mandy, W., Midouhas, E., Flouri, E., \& Cable, N. (2020). Determinants of an autism spectrum disorder diagnosis in childhood and adolescence: Evidence from the UK Millennium Cohort Study. Autism, 24 (6), 1557-1565.

[6] Wan, Y., Hu, Q., Li, T., Jiang, L., Du, Y., Feng, L.,... \& Li, C. (2013). Prevalence of autism spectrum disorders among children in China: a systematic review. Shanghai Archives of Psychiatry, 25 (2), 70. 
[7] Martin-Cantero, A., Reijnierse, E. M., Gill, B. M., \& Maier, A. B. (2021). Factors influencing the efficacy of nutritional interventions on muscle mass in older adults: a systematic review and meta-analysis. Nutrition reviews, 79 (3), 315-330.

[8] Pigott, T. D., \& Polanin, J. R. (2020). Methodological guidance paper: High-quality meta-analysis in a systematic review. Review of Educational Research, 90 (1), 24-46.

[9] Chiarotti, F., \& Venerosi, A. (2020). Epidemiology of autism spectrum disorders: a review of worldwide prevalence estimates since 2014. Brain sciences, 10 (5), 274.

[10] Kyaga, S., Net, P., Lehner-Martin, V., Beillat, M., \& Falissard, B. (2020). P. 117 Prevalence of autism in Europe and the United States. European Neuropsychopharmacology, 40, S72-S73.

[11] Cardinal, D. N., Griffiths, A. J., Maupin, Z. D., \& Fraumeni-McBride, J. (2021). An investigation of increased rates of autism in US public schools. Psychology in the Schools, 58 (1), 124-140.

[12] Hong, M., Lee, S. M., Park, S., Yoon, S. J., Kim, Y. E., \& Oh, I. H. (2020). Prevalence and economic burden of autism spectrum disorder in South Korea using national health insurance data from 2008 to 2015. Journal of autism and developmental disorders, 50 (1), 333-339.
[13] Kita, Y., Ashizawa, F., \& Inagaki, M. (2020). Prevalence estimates of neurodevelopmental disorders in Japan: A community sample questionnaire study. Psychiatry and clinical neurosciences, 74 (2), 118-123.

[14] Yang, C., Zhang, L., Zhu, P., Zhu, C., \& Guo, Q.. (2016). The prevalence of tic disorders for children in china: a systematic review and meta-analysis. Medicine, 95 (30), e4354.

[15] Loth, E., \& Evans, D. W. (2019). Converting tests of fundamental social, cognitive, and affective processes into clinically useful bio-behavioral markers for neurodevelopmental conditions. Wiley Interdisciplinary Reviews: Cognitive Science, 10 (5), e1499.

[16] Roestorf, A., Bowler, D. M., Deserno, M. K., Howlin, P., Klinger, L., McConachie, H.,... \& Geurts, H. M. (2019). "Older Adults with ASD: The Consequences of Aging." Insights from a series of special interest group meetings held at the International Society for Autism Research 2016-2017. Research in autism spectrum disorders, 63, 3-12.

[17] Russell, G., Mandy, W., D Elliott, White, R., Pittwood, T., \& Ford, T.. (2019). Selection bias on intellectual ability in autism research: a cross-sectional review and meta-analysis. Molecular Autism, 10 (1). 